\title{
Adverse impact of STATCOM on the performance of distance relay
}

\begin{abstract}
FACTS devices like the Static Synchronous Compensator (STATCOM), are mostly used to enhance the maximum power transfer capability of the transmission Line (TL) system. A Matlab simulation model of Distance Relay protection of TL, with connected STATCOM at the mid-point for optimum power transfer is presented. The STATCOM's impact on the operation of the relay is assessed with the effects on the relay misoperation in the third zone of protection coverage, during fault conditions, in four different locations. The wrong measured fault impedance by relay resulted to misoperation in zone 3 (under reach phenomena). The simulation result indicates a slight increase in the measured impedance of $1.33 \Omega$ over the actually expected impedance setting $(72.02 \Omega)$ of the relay at $220 \mathrm{~km}$ protection coverage of zone 3 along the TL. This variation is about $4 \mathrm{~km}$ distance outside the expected distance protection coverage for fault in zone 3 as proven.
\end{abstract}

Keyword: FACTS; STATCOM; Distance relay; Impedance; Model 